\title{
La política comercial de la Unión Europea:
}

\section{hacia un comercio más} justo para todos

\section{Monserrat García}

Licenciada en ciencias económicas y empresariales de la Universidad de Valladolid / Universidad Católica de Lovaina. Miembro de la Delegación de la Comisión Europea en Colombia, responsable de asuntos económicos y comerciales.

correo electrónico monserrat.garcia-villanueva@cec.eu.int

A pesar del crecimiento experimentado en los intercambios comerciales, la explosión de las tecnologías de la Información y la Comunicación, etc., en la mayor parte de las regiones del planeta (todas menos países del Este de Asia) entre 1990 y 2000 el número de personas que subsisten con menos de US\$1 por día, no sólo no se vio reducido, sino que aumentó.

¿Por qué el crecimiento económico no ha venido acompañado por una reducción de la pobreza? O en otras palabras, ¿cuáles son las condiciones o mecanismos necesarios para que los beneficios de la intensificación del comercio y el creci- miento económico se extiendan a toda la población del planeta?:

- Se necesitan ciertas "reglas del juego", la existencia de instituciones nacionales e internacionales que pongan en marcha políticas de redistribución de estos beneficios generados por la globalización.

- Es necesario que los países en desarrollo tengan las mismas oportunidades de insertarse en el comercio internacional que los desarrollados, pudiendo así explotar a nivel global las ventajas comerciales de que dispongan (materias 
primas, manufacturas, etc.).

La evolución del comercio de la UE siempre ha ido en ascenso. La progresiva apertura y liberalización de nuestro mercado ha sido objetivo de la UE desde su constitución, lo que ha contribuido con esta positiva evolución de las cifras comerciales.

Así desde los años 60, constituimos una «unión aduanera» que implicó que un país miembro podía comerciar cualquier cantidad de bienes con cualquier otro país miembro sin tener que pagar derechos de aduana. Más adelante adoptamos un "arancel externo común», lo que significa que se aplicaba el mismo derecho de aduana a los productos importados procedentes de países no miembros, independientemente del país miembro que los importara.

Pero, pese a que se eliminaron los obstáculos arancelarios, siguió habiendo obstáculos «no arancelarios» (trámites administrativos y las normas sobre aspectos como el envasado y el etiquetado) variaban de un país a otro. En 1992 la UE puso en marcha el «mercado único», eliminando de este modo los obstáculos «no arancelarios» al comercio de mercancías y abriendo también el comercio de servicios dentro de la UE.

Paralelamente, la UE viene trabajando en la liberalización de su comercio frente al resto del mundo, a través de su acción en el seno de la OMC y sus relaciones bilaterales con países y regiones.
En la actualidad, la UE es la primera potencia comercial del mundo, con más del $20 \%$ de las importaciones y las exportaciones mundiales.

El comercio fue uno de los primeros campos en que los países de la UE acordaron unir su soberanía, transfiriendo a la Comisión Europea la responsabilidad de ocuparse de los asuntos comerciales, incluida la negociación en nombre de dichos países de los acuerdos de comercio internacionales, de manera que los quince estados miembros de la UE negocian como uno solo, tanto con sus socios comerciales como en la OMC, con lo que maximizan su influencia en el ámbito internacional.

Con la ampliación de la UE a sus 10 nuevos estados en 2004, UE se convierte en la economía de mayor peso a nivel mundial: PIB de 9,7 billones de euros (millones de millones), supera el alcanzado por EE.UU.

La UE cuenta con una población de casi 500 millones y un Producto Interno Bruto de 30\% del PIB mundial. El grado de inserción de la UE es el mayor del resto de bloques económicos, a excepción de China.

Respecto al comercio que mantiene la UE con los países en desarrollo, ésta se sitúa claramente a la cabeza.

- Entre 1990 y 2000 las importaciones realizadas por la UE a los PVD se duplicaron, alcanzando el 52\% del total. Somos, muy por encima del resto, los principales importadores de mercancías 
procedentes de los denominados PMA o Países Menos Adelantados.

- Los gráficos muestran la evolución de las importaciones de mercancías a los PVD en general así como a los 49 PMA. Vemos que la tendencia es básicamente al crecimiento entre 1999 y 2003.

- Lo mismo ha ocurrido con las exportaciones de la UE a estos países, la tendencia, como vemos, se mantiene constante.

Una de las principales consecuencias del proceso de integración de la UE ha sido, como hemos indicado ya, la creación y perfeccionamiento de una política comercial común para el conjunto de los 25 países que integramos la Unión.

El Tratado de Roma estableció como objetivo crear entre los estados miembros una unión aduanera donde los intercambios estarían libres de todo obstáculo y se aplicaría un arancel exterior común a las importaciones procedentes de terceros estados.

Paulatinamente, la expansión del comercio internacional hizo de la política comercial común una de las más importantes de la Comunidad. Al mismo tiempo, las sucesivas ampliaciones y la consolidación del mercado común reforzaron la posición de la Comunidad como polo de atracción e influencia sobre las negociaciones comerciales, bilaterales con terceros estados o multilaterales en el marco del GATT (y actualmente, dentro de la OMC). Progresivamente, la Unión ha ido tejiendo una densa red de relaciones comerciales a escala mundial.

Sin embargo, la capacidad de la Unión para desempeñar un papel clave en las negociaciones globales depende más de la eficacia de su política comercial común que del volumen de sus intercambios.

Desde el 1 de enero de 1970, las decisiones que dependen de la política comercial común se toman por mayoría cualificada en el Consejo.

El artículo 133 del Tratado constitutivo de la Comunidad Europea, regula el ejercicio de la Política Comercial Común de la UE y confía un papel de negociador único a la Comisión Europea en el marco de los mandatos específicos que le concede el Consejo. En la práctica, una serie de procedimientos de coordinación ad hoc permiten asociar a los estados miembros a cada una de las fases de la negociación llevada a cabo por la Comisión.

La política comercial de la UE, responde a unos intereses básicos:

1. Es un medio para difundir valores europeos: democracia, Estado de derecho, medio ambiente, respeto de los derechos sociales, etc.

2. Busca la apertura de los mercados al comercio mundial: eliminación de barreras al comercio.

3. Pretende la inserción de todos los países 
en el sistema de comercio internacional.

En este sentido, la política comercial de la UE está íntimamente ligada al desarrollo: desde la UE reconocemos el rol del comercio como actor del desarrollo y el crecimiento. Creemos firmemente que, acompañado por las politicas apropiadas, el comercio puede reducir la pobreza.

Esta búsqueda de la integración equitativa de los países pobres en la economía mundial y el sistema comercial internacional, es ejercitada por la UE a través de tres vías:

\section{La vía multilateral:}

En el seno de la Organización Mundial de Comercio (OMC) en este momento se trabaja por alcanzar los objetivos establecidos en la Agenda de Desarrollo de Doha (ADD). A través de esta agenda, por primera vez los miembros de la OMC han decidido situar en el centro de las negociaciones el tema del desarrollo, reconociendo la necesidad de los países pobres de explotar plenamente las posibilidades del sistema comercial multilateral. Se trata de establecer reglas que favorezcan el desarrollo, permitiendo a estos países sacar mayor provecho de la progresiva liberalización de los intercambios.

En este sentido, la UE está poniendo un gran empeño en el éxito del Programa de Doha, habiendo realizado importantes propuestas en distintos campos, tales como:
- El acceso al mercado de productos industriales de los países en desarrollo;

- La apertura de los mercados agrícolas;

- La liberalización de los servicios, con condiciones especiales para los países pobres;

- La facilitación de los intercambios, protegiendo a los países en desarrollo contra las prácticas discriminatorias;

- El tratamiento especial y diferenciado a los PVD;

- Y el refuerzo de las capacidades de los países pobres con el fin de aprovechar al máximo las ventajas de la apertura comercial.

El segundo pilar de la política comercial comunitaria a favor del desarrollo, se sitúa a nivel bilateral: esta interrelación entre comercio y desarrollo perseguida desde la UE, queda claramente plasmada en las relaciones bilaterales de Europa con los países menos aventajados. Los Acuerdos de Asociación Económica (AAE) son un buen ejemplo de ello. Negociados con los países ACP (África, Caribe y el Pacífico), estos Acuerdos están al servicio del desarrollo sostenible, contribuyen a reforzar la integración regional y a mejorar el clima de negocios en estos países.

Mirando hacia América Latina, si bien las relaciones bilaterales de esta región 
con Europa se remontan a siglos atrás, desde los años 60, la Unión Europea ha establecido y reforzado los vínculos con el subcontinente. Durante las tres últimas décadas, la relación entre ambas regiones se ha desarrollado de manera extraordinaria. A la fecha de hoy, la UE cuenta con Acuerdos de Asociación con países como Chile o México y se encuentra en negociaciones con los principales bloques de la región: MERCOSUR, Mercado Común Centroamericano y próximamente con la Comunidad Andina.

Desde la UE consideramos que la integración económica de toda la región, incluida la Comunidad Sudamericana de las Naciones, constituye un elemento esencial para el desarrollo de los sectores productivos y para la aparición de un auténtico mercado regional, capaz de hacer frente, llegado el caso, a los retos derivados de un acuerdo de libre comercio con la UE. Habida cuenta de la dimensión francamente reducida de algunos países, la UE y América Latina tienen el máximo interés en beneficiarse de un mercado regional unificado que ofrezca más perspectivas a los agentes económicos y en cuyo interior los bienes y servicios puedan circular libremente.

De forma paralela a las negociaciones en curso, la UE desea reforzar y dar más estabilidad al diálogo con sus principales socios comerciales de América Latina sobre los obstáculos existentes y potenciales para el desarrollo de los intercambios y de las inversiones.
Por último, cabe mencionar una tercera vía de implementación de la política comercial comunitaria a favor del desarrollo: la que se realiza de manera unilateral.

La UE es el mayor proveedor mundial de preferencias comerciales a favor de países en vías de desarrollo y el mayor importador de productos agrícolas, superando al resto de los países desarrollados como Estados Unidos y Japón.

Desde hace más de tres décadas, la UE viene desarrollando un sistema que va más allá de los horizontes bilaterales y multilaterales. Se trata de un mecanismo unilateral y no recíproco, que otorga un acceso privilegiado en el mercado europeo a los productos procedentes de países en desarrollo: el Sistema de Preferencias Generalizadas (SPG). La UE fue la primera en poner en marcha un instrumento de esta naturaleza en 1971. Desde entonces, los países en desarrollo se benefician de una reducción o eliminación de aranceles en la mayor parte de los productos que exportan a Europa. El esquema ha sido renovado en numerosas ocasiones, la última a inicios de 2006 y hasta 2013.

Todos los países de América Latina que no cuentan con un acuerdo comercial con la UE se benefician del SPG, pudiendo de este modo incrementar sus exportaciones a Europa. Más que una herramienta para mejorar el acceso de los productos latinoamericanos al mercado comunitario, es una oportunidad y una puerta abierta a las exportaciones de la región. 
Firma de 27 convenciones internacionales referentes a medio ambiente, gobernabilidad. Colombia suscribió todas.

\section{Ámbito regulatorio: el nuevo artículo 133 del tratado constitutivo de la Comunidad Europea}

Recientemente se ha añadido un nuevo apartado al artículo 133 (antiguo artículo 113) del Tratado Constitutivo de la Comunidad Europea. Éste prevé que el Consejo, previa consulta al Parlamento europeo, pueda extender el ámbito del artículo 133 a las negociaciones y acuerdos internacionales relativos a los servicios y a los derechos de la propiedad intelectual en la medida en que ya no están incluidos en el ámbito de la política comercial común.

La adición de este apartado permitirá a la Unión evitar un debate que implicaría una modificación del Tratado (lo cual es solamente posible mediante una Conferencia intergubernamental y la ratificación de cada Estado miembro) en el caso de que se decidiese ampliar el ámbito del procedimiento tradicional de negociación comercial.

Concretamente, podrá tomarse una decisión ampliando las competencias comerciales de la Comunidad por unanimidad de los miembros del Consejo.

El Tratado CE establece la misión y objetivos generales de la política comercial de la UE:

El artículo 2 establece los objetivos generales, que incluyen el fomento y desarrollo de las actividades económicas, un alto nivel de empleo y de competitividad y la protección del medio ambiente.

Los artículos 131 y 133 explican el modo en el que operará en principio la política comercial común, "contribuir, conforme al interés común, al desarrollo armonioso del comercio mundial, a la supresión progresiva de las restricciones a los intercambios internacionales y a la reducción de las barreras arancelarias". Instrumentos y ámbito: el artículo 133 establece el ámbito, los instrumentos y los procedimientos de toma de decisiones.

El artículo 300 establece el actual procedimiento interinstitutional para la celebración de acuerdos internacionales, principalmente por el Consejo, que en la actualidad no está legalmente obligado a consultar al Parlamento europeo para los acuerdos comerciales; no obstante, de hecho se realizan esas consultas.

La nueva Constitución de la UE, propone una serie de cambios en el seno de la política comercial común de la UE. En realidad, se trataría de:

- Ampliar las competencias de la CE en materia de comercio comunitario: inversión extranjera directa.

- Ampliar el papel del PE: informando de procesos de negociación comercial con terceros e interviniendo a través de co-decisión o dictamen.

Si nos referimos al funcionamiento de la política comercial de la UE, es necesario 
citar los instrumentos con los que se aplica dicha politica:

A) Instrumentos "defensivos": para garantizar el comercio justo y defender los intereses de las empresas europeas, conforme a los acuerdos especificos de la OMC que reconocen el derecho de los miembros a hacer frente a las prácticas desleales:

- Medidas anti-dumping para contrarrestar la práctica distorsionadora del comercio más frecuente. Hay dumping cuando los fabricantes de un país no perteneciente a la UE venden en la misma mercancías a un precio más bajo que el que tienen en su mercado interior, o por debajo del coste de producción.

- Medidas anti-subsidio para oponerse a los subsidios que las autoridades públicas conceden a los fabricantes y que también pueden alterar el comercio si contribuyen a reducir los costes de producción o reducen de manera injusta los precios de las exportaciones a la UE.

- Salvaguardias: Un miembro de la OMC puede restringir temporalmente las importaciones de un producto si su industria se ve gravemente perjudicada o amenazada por un aumento de las mismas.

B) Instrumentos "ofensivos" destinados a abrir los mercados y eliminar los obstáculos al comercio en el ámbito multilateral, en el bilateral y en el unilateral:
- El reglamento sobre los obstáculos al comercio, proporciona a la industria la oportunidad de presentar una queja ante la Comisión cuando haya razones para pensar que existen barreras que limitan el acceso de las empresas a los mercados de terceros países. También se puede utilizar el reglamento para evaluar si existen pruebas de una violación de las normas del comercio internacional que haya repercutido negativamente en el comercio: esto podría poner en marcha el mecanismo de solución de diferencias de la OMC (ver a continuación).

- La estrategia de apertura de los mercados. La base de datos de acceso al mercado de la UE facilita: información sobre las condiciones de acceso al mercado en países de fuera de la UE; un modo sistemático de seguimiento por la Comisión de las quejas de los empresarios sobre los obstáculos al comercio en esos países; además, es un medio de garantizar el cumplimiento de los compromisos internacionales contraidos por nuestros socios comerciales.

En la actualidad, la política comercial de la UE se dirige claramente hacia una nueva generación de Acuerdos de Libre Comercio con países que superan, incluso, el ámbito comercial.

La unidad encargada de los asuntos comerciales en el seno de la Comisión Europea, es la Dirección General de Comercio. 
Entre las competencias de dicha dirección general, las más importantes serían:

- La negociación de acuerdos bilaterales, regionales o multilaterales sobre la base de directivas de negociación preparadas por la misma y adoptadas por el Consejo.

- Vigilar y asegurar la puesta en marcha de los acuerdos internacionales, a través del sistema de solución de los controversias de la OMC y los instrumentos de promoción o de defensa comercial de la UE.

- Participar en la elaboración y seguimiento de políticas internas o externas que afecten al comercio de los países de la UE.

- Asegurar, en el marco del grupo Relex, la coherencia entre la política comercial y la política general.

- Asegurar una información clara, completa y rápida: a los interlocutores económicos, sociedad civil, etc.

Pasemos a hablar de cómo se materializa nuestra política comercial en Colombia.

Aproximadamente el $63 \%$ de las exportaciones colombianas a la UE están totalmente liberadas por NMF o SPG General, entre ellas: carbón, café y ferroníquel (exportaciones tradicionales).
Por otro lado, aproximadamente el $17 \%$ de las exportaciones colombianas a la UE se benefician del SPG Plus, casi todas con cero arancel.

El 20\% restante se encuentra gravado, pero de este porcentaje, el $18 \%$ corresponde al banano.

En definitiva, el $80 \%$ del total de las exportaciones colombianas están liberadas en el mercado europeo.

Paralelamente, la Comisión Europea ha puesto en marcha en Colombia una serie de instrumentos de apoyo a la exportación que están arrojando excelentes resultados, especialmente en lo referente a la PYME colombiana y su proyección hacia Europa.

\section{El programa AL-INVEST de la CE}

Históricamente Europa y América Latina han establecido fuertes lazos económicos. Para fortalecer esta cooperación económica la Comisión Europea lanzó en 1993 el Programa AL-INVEST, concebido como una red de operadores de Europa y de América Latina que cooperan en la organización de encuentros sectoriales de empresas activas de un mismo sector en los dos lados del Atlántico.

Desde 1993, a través de este instrumento se ha apoyado exitosamente a miles de PYME y organizaciones de todos los sectores económicos, facilitando el comercio y la inversión entre ambos continentes. Para consolidar dicho éxito, en 2004 comenzó una nueva fase del pro- 
grama, AL-INVEST III, que estará en vigor durante cuatro años y con una dotación de 42 millones para el conjunto de países latinoamericanos. En la actualidad existen más de 200 organizaciones en la Unión Europea y América Latina que forman parte de la red AL-INVEST III y sólo los miembros de la misma tienen acceso a los fondos del programa.

La participación de Colombia en AL-INVEST se desarrolla a través de los cuatro EUROCENTROS existentes, ubicados en Bogotá, Cartagena, Manizales y Medellín. Colombia ha colaborado en 85 de las 464 actividades organizadas por el Programa AL-INVEST, involucrando 505 compañías, lo que supone una tasa de participación de $20.21 \%$. El valor de los contratos firmados entre empresas europeas y Colombianas asciende a 1,627,800 euros cubriendo una amplia gama de sectores como café, flores y plantas, agroindustria, maquinaria y equipamiento. Sin embargo, tan sólo el 3,6\% de las iniciativas desarrolladas por AL-INVEST, han contado con un Eurocentro colombiano como operador principal del proyecto.

Las actividades previstas en esta nueva fase de AL-INVEST III, se agrupan en cinco áreas:

- Capacitación para PYME: seminarios, talleres y otras actividades de formación sobre estrategias de internacionalización para PYME y capacitación técnica sectorial.

- Semanas Europeas - Semanas Latinoa- mericanas: organización de visitas de prospección a ferias internacionales, asistencia personalizada a las empresas participantes.

- Encuentros sectoriales: personalizados entre compañías europeas y latinoamericanas.

- Facilidad para el desarrollo de negocios: asistencia personalizada y búsqueda activa de socios del otro continente para desarrollar un plan de negocios conjunto.

- Colaboración entre PYME: asistencia técnica y apoyo a empresas europeas y latinoamericanas en la etapa de seguimiento de acuerdos comerciales.

Por otro lado, existe la posibilidad de financiar actividades de formación institucional a través de tres vías:

- Capacitación de operadores (formación para operadores de la red AL-INVEST III);

- Intercambio de funcionarios (intercambios de formación individuales para ejecutivos de organizaciones empresariales);

Actividades conjuntas (como mecanismo de apoyo para el desarrollo de proyectos conjuntos entre operadores europeos y latinoamericanos). 


\section{Promoviendo las exportaciones de PVD hacia la UE: El Export Helpdesk}

Una herramienta importante que la CE ha puesto a disposición de todos los exportadores de países emergentes, es el denominado Export HelpDesk. Se trata de una base de datos en Internet creada por la DG TRADE de la Comisión europea para facilitar el acceso de las exportaciones de los países en desarrollo a los mercados de la UE.

Esta base de datos cuenta con dos fuentes de información:

- Un primera fuente, que comprende información relativa a derechos de importación, documentación aduanera, normas de origen, estadísticas comerciales, enlaces, espacio comercial y contactos. Todas estas secciones se pueden consultar en inglés, francés, español y portugués.

- La segunda, consiste en un servicio en línea que responde a preguntas sobre situaciones reales y problemas con los que se enfrentan los exportadores de los países en desarrollo.

Aunque este servicio se ha creado para los exportadores de los países en desarrollo, hay que reconocer que también lo utilizan los importadores de la UE. Los exportadores de los países en desarrollo necesitan un socio en la UE, así que no es sorprendente que los veinticinco estados miembros de la
UE se beneficien también de este servicio (por ejemplo, algunas veces recibimos preguntas en nuestro buzón procedentes de importadores de la UE que quieren saber si un exportador de un país en desarrollo está ya inscrito en la lista de establecimientos del "país X" autorizados por la CE para exportar su producto a la UE).

Por último, la Comisión europea está poniendo en marcha en Colombia un programa de asistencia técnica relativa al comercio.

A partir de los principios establecidos en Doha, Monterrey y Johanesburgo, la Comisión europea ha adoptado hoy un plan de acción para promover los esfuerzos de los países en desarrollo, para beneficiarse del comercio.

En la comunicación al Consejo y al Parlamento europeos titulada 'Comercio y desarrollo: Ayudar a los países en desarrollo a beneficiarse del comercio', se destaca la importancia de la relación entre desarrollo, comercio e integración de los países en desarrollo en la economía mundial. La comunicación concluye con una serie de métodos prácticos con los que la Unión Europea se propone ayudar a los países en desarrollo en su esfuerzo por aprovechar mejor el sistema mundial de comercio, incluido un reajuste de la financiación de la asistencia relacionada con el comercio, en caso necesario, en colaboración con países socios.

El plan de la Comisión incluye desde medidas para mejorar la prestación de la asistencia relacionada con el comercio 
en áreas clave hasta ideas para lograr una mejor coordinación y coherencia política dentro de la UE y con las organizaciones internacionales. En líneas generales, las medidas deberán ayudar a los países en desarrollo, y en especial a los menos desarrollados, a adquirir una capacidad reglamentaria institucional y la capacidad de asumir los aspectos técnicos del comercio en un sistema mundial. Al mismo tiempo, la Comisión hace hincapié en la importancia de que los países en desarrollo mejoren el entorno de inversión para el sector empresarial y garanticen que los pobres puedan beneficiarse plenamente de los intercambios comerciales.

A partir de 2007, Colombia contará con un programa propio de TRA, en función de las necesidades del país y de las demandas planteadas por los principales operadores comerciales colombianos.

De lo dicho hasta ahora, podemos concluir que la globalización ha hecho que las cuestiones comerciales preocupen a los ciudadanos más que nunca. La apertura de los mercados, gestionada de manera eficiente, puede crear oportunidades para los países si está controlada por una normativa colectiva, contribuyendo con el crecimiento económico y la reducción de la pobreza.

Gracias a los esfuerzos realizados por los distintos países y bloques comerciales en el seno de la OMC y a través de sus relaciones comerciales bilaterales, conseguiremos alcanzar un comercio más justo para todos.
Para finalizar, cabe hacer mención de los desafíos futuros a los que se enfrenta la política comercial de la UE hacia el exterior, y en especial hacia Colombia como socio estratégico. Estos desafíos podrían resumirse en los siguientes puntos:

- Continuar nuestro trabajo en torno al lazo entre comercio y desarrollo y la integración de los países en desarrollo, en concreto Colombia en la economía mundial.

- La conclusión de la ronda de Doha.

- Reducción a la protección interna UE.

- Profundización de acuerdos comerciales: en el caso de Colombia, la futura firma de un Acuerdo Asociación UE - CAN.

Apoyo en estándares y normas internacionales.

- Apoyo a Colombia en el aprovechamiento de las ventajas comerciales ofrecidas por la UE: SPG Plus.

- Puesta en marcha de un programa bilateral de TRA y proyectos de cooperación comercial. 
García, Monserrat.

"La política comercial de la Unión Europea: hacia un comercio más justo para todos", en Oasis 2006-07, núm. 12, Centro de Investigaciones y Proyectos Especiales, CIPE, Facultad de Finanzas, Gobierno y Relaciones Internacionales. Universidad Externado de Colombia, pp. 347-357. 